\title{
Nanotechnology in Plant Science: To Make a Long Story Short
}

\author{
Ilaria Sanzari ${ }^{1}$, Antonietta Leone ${ }^{2}$ and Alfredo Ambrosone ${ }^{2 *}$ \\ ${ }^{1}$ Faculty of Engineering and the Environment, University of Southampton, Southampton, United Kingdom, ${ }^{2}$ Department of \\ Pharmacy, University of Salerno, Fisciano, Italy
}

This mini-review aims at gaining knowledge on basic aspects of plant nanotechnology. While in recent years the enormous progress of nanotechnology in biomedical sciences has revolutionized therapeutic and diagnostic approaches, the comprehension of nanoparticle-plant interactions, including uptake, mobilization and accumulation, is still in its infancy. Deeper studies are needed to establish the impact of nanomaterials (NMs) on plant growth and agro-ecosystems and to develop smart nanotechnology applications in crop improvement. Herein we provide a short overview of NMs employed in plant science and concisely describe key NM-plant interactions in terms of uptake, mobilization mechanisms, and biological effects. The major current applications in plants are reviewed also discussing the potential use of polymeric soft NMs which may open new and safer opportunities for smart delivery of biomolecules and for new strategies in plant genetic engineering, with the final aim to enhance plant defense and/or stimulate plant growth and development and, ultimately, crop production. Finally, we envisage that multidisciplinary collaborative approaches will be central to fill the knowledge gap in plant nanotechnology and push toward the use of NMs in agriculture and, more in general, in plant science research.

\section{Keywords: nanomaterials, nanogels, plant nanobiotechnology, plant protection, nanosensors, advanced genetic engineering}

${ }^{*}$ Correspondence:

Alfredo Ambrosone aambrosone@unisa.it

Specialty section:

This article was submitted to Nanobiotechnology,

a section of the journal Frontiers in Bioengineering and

Biotechnology

Received: 31 January 2019 Accepted: 07 May 2019

Published: 29 May 2019

Citation:

\section{INTRODUCTION}

Nanomaterials have unique physicochemical properties and provide versatile scaffolds for functionalization with biomolecules. Moreover, certain NMs such as gold and magnetic nanoparticles as well as polymeric or hybrid NMs have shown to respond to external stimuli achieving a spatiotemporal controlled release of macromolecules. For these reasons, over the last two decades, engineered nanomaterials have been successfully tested and applied in medicine and pharmacology, especially for diagnostic or therapeutic purposes (Bruchez et al., 1998; Tang et al., 2006; Perrault et al., 2009). More recently, the field of nanotechnology is gaining an increased interest in plant science, especially for the application of nanomaterials (NMs) as vehicles of agrochemicals or biomolecules in plants, and the great potential to enhance crop productivity (Khan et al., 2017).

It is reasonable to argue that the potentiality and the benefits of the application of NMs in plant sciences and agriculture are still not fully exploited, due to some bottlenecks, which can be briefly summarized as follows: (i) the need to design and synthesis safe NMs which do not interfere negatively with plant growth and development (Sabo-Attwood et al., 2012); (ii) the lack 
of knowledge on the exact mechanisms of NMs uptake and mobilization in plants (Ranjan et al., 2017) and, (iii) the lack of multidisciplinary approaches, necessary for the design and the implementation of nanotechnology applications in plants.

\section{NANOMATERIALS IN PLANT SCIENCE}

According to ASTM standards, Nanomaterials (NMs) can be defined as natural or manufactured materials, typically ranging between 1 and100 nm (Astm E2456 - 06, 2012). NMs have a small size and a high surface-to-volume ratio, which confer to them remarkable chemical and physical properties in comparison to their bulk counterparts (Roduner, 2006). NMs have unique and versatile physicochemical properties, which makes their use suitable in different fields, such as life science, electronics and chemical engineering (Jeevanandam et al., 2018). Recently, nanotechnology is gaining interest also in plant science, due to the need to develop miniaturized efficient systems to improve seed germination, growth and plant protection to abiotic and biotic stresses (Wang et al., 2016).

Metallic nanoparticles (NPs), such as gold (Au), and silver (Ag) NPs, have been widely introduced in plant science for different applications (Figure 1A). Their chemical synthesis is quite costly and requires the use of hazardous chemicals (Viswanath and Kim, 2015; Rastogi et al., 2019). However, greener approaches based on the use of plant extract as well as ionizing radiation chemistry in aqueous solutions have been developed (Abedini et al., 2013). Also oxidized NMs, such as $\mathrm{MgO}, \mathrm{CaO}, \mathrm{ZnO}$, and $\mathrm{TiO}_{2} \mathrm{NMs}$, have been widely proposed, thanks to their superior electrical, catalytic and light absorption properties (Jahan et al., 2018). Over the recent years, the interest in polymeric nanomaterials is predominantly increasing due to their biocompatibility, lowcost synthesis and capability to response to external stimuli (Baskar et al., 2018). Core/Shell NPs are also available and can be manufactured with a variety of combination of materials such as inorganic/inorganic, inorganic/organic, organic/inorganic, and organic/organic materials. The choice of the shell of the NPs strongly depends on the end application and use (Ghosh Chaudhuri and Paria, 2012). For example, polymeric shells have been proposed to improve the biocompatibility of the NPs (Nath et al., 2008). NPs with a nanostructured shell have been also synthesized, such as mesoporous silica nanoparticles (NPs) made from a mesoporous structure with a highly functionalizable surface area (Torney et al., 2007).

Nanogels (NGs) are a new category of NM with a growing interest in the nanotechnology community. They have excellent physicochemical properties, colloidal stability, high encapsulation capacity of biomolecules (bioconjugation), and stimuli-responsiveness $(\mathrm{pH}$, temperature, etc.). NGs are defined as nano-sized ionic and non-ionic hydrogels made of synthetic or natural polymeric chains, chemically or physically cross-linked (Molina et al., 2015; Neamtu et al., 2017). NGs possess a high water content $(70-90 \%$ of the entire structure), a high degree of porosity and high load capacity. The most common NGs are chitosan, alginate, poly(vinyl alcohol), poly(ethylene oxide), poly(ethyleneimine), poly (vinylpyrrolidone), poly(N-isopropylacrylamide). NGs with hybrid structures, made of polymeric or non-polymeric materials can be obtained (Molina et al., 2015). Hybrid NGs have been classified in: (i) nanomaterial- nanogel, which are synthesized by incorporation of nanosized materials such as magnetic or carbonaceous nanoparticles, and (ii) polymernanogel composites, which include interpenetrated networks (IPNs), copolymer, and core-shell particles (Molina et al., 2015). The main advantage of IPNs and copolymer NGs relies on their stimuli-responsiveness, whereas core-shell NGs are more promising for encapsulating biomolecules and drug delivery.

\section{NANOPARTICLE UPTAKE, TRANSLOCATION, AND BIOLOGICAL IMPACT IN PLANTS}

Applications of nanotechnology strategies in plants need a preventive accurate evaluation of nanoparticle-plant interactions, including the comprehension of the mechanisms of their uptake, translocation and accumulation, together with the assessment of potential adverse effects on plant growth and development. Plant uptake of NPs is hardly predictable, depending on multiple factors related to the nanoparticle itself (size, chemical composition, net charge and surface functionalization), but also on the application routes, the interactions with environmental components (soil texture, water availability, microbiota), the constraint due to the presence of a cell wall, the physiology and the multifaceted anatomy of individual plant species. Most of the previous studies in plants deal with the uptake of small metal and metal oxide NPs, due to the wide use in industry and to the easy detection and tracking by microscopy techniques (González-Melendi et al., 2008). However, compared to the great wealth of information available in metazoans, only a handful of integrated comparative analyses have been conceived to establish the contribution of the physicochemical features (e.g., size, charge, coatings, etc.) of NPs in plant-nanoparticle interaction (Zhu et al., 2012; Song et al., 2013; Moon et al., 2016; Vidyalakshmi et al., 2017; García-Gómez et al., 2018).

\section{Delivery Methods and Primary Interactions at the Plant Surface}

Basically, engineered nanomaterials can be applied either to the roots or to the vegetative part of plants, preferentially to the leaves (Figure 1B). At the shooting surface, NPs can be taken up passively through natural plant openings with nano- or microscale exclusion size, such as stomata, hydathodes, stigma and bark texture (Eichert et al., 2008; Kurepa et al., 2010). However, additional plant anatomical and physiological aspects need to be considered to better understand the dynamics of NP-plant interactions. For instance, shoot surfaces are generally covered by a cuticle made of biopolymers (e.g., cutin, cutan) and associated waxes, which function as a lipophilic barrier to protect above-ground plant primary organs, leaving access only through natural openings (Figure 1B). Dynamics of NPs at the cuticle level are poorly investigated, but at present, this barrier appears to 




FIGURE 1 | (A) Illustration of NMs grouped into several categories: carbon-based NMs such as fullerenes and carbon nanotubes, including single-walled carbon nanotubes (SWCNTs) or multi-walled carbon nanotubes (MWCNTs); metallic NPs, including metals such as gold (Au), silver (Ag), aluminum (Al); metal oxides (ZnO, $\mathrm{CuO}, \mathrm{TiO}_{2}, \mathrm{Fe}_{2} \mathrm{O} 3, \mathrm{SiO}_{2}$, etc.); quantum dots (QDs); dendrimers, which are three dimensional polymer network immensely branched with low polydispersity and liposomes and nanogels. With the development of new techniques for chemical synthesis, it is possible to synthesize NMs not only with a symmetrical (spherical) shape but also having a variety of different nanoforms, such as nanoclays (polypropylene nanoclay systems) and nanoemulsions (lipophilic nanoemulsions), tubes, rods, disks, bars, and sheets. (B) Schematization of different NP delivery methods and translocation in plants. Nanoparticle can be administered both at foliar and root system. Once penetrated the external layers, they move through the symplastic or apoplastic routes and reach different organs and tissues. (C) Currently, the main focus of the publications in plant science deals with the use of NPs as biosensors or biomolecules nanocarriers for crop production and protection under controlled conditions. New advances in DNA/miRNA/siRNA delivery have found limited application in plant so far, while new nanotechnology tools addressing technical concerns in genome editing strategies are strongly demanded.

be an almost impenetrable layer to nanoparticles, although nano$\mathrm{TiO} 2$ has been shown to be able to produce holes in the cuticle (Larue et al., 2014; Schwab et al., 2016). Trichomes on plant organs can affect dynamics at the plant surface by entrapping NP on the plant surface and thus increasing the permanence time of exogenous materials on tissues. Damages and wounds may also function as viable routes for NP internalization in plants in both aerial and hypogeal parts (Al-Salim et al., 2011). Delivery methods also seem to influence NP uptake efficiency in plants. As recently reported, the aerosol application promotes higher internalization rates of different nanoparticles with respect to NP drop cast in watermelon (Raliya et al., 2016). Also, leaf lamina infiltration strategies may force NM penetration in plant tissues as reported for single-walled carbon nanotubes (Giraldo et al., 2014) and resulted to be functional for gene delivery (Demirer et al., 2018). At the root level, rhizodermis lateral root junctions may provide easy access to NMs, especially near the root tip, while upper parts are impermeable due to the presence of suberin (Chichiriccò and Poma, 2015). Generally, the dynamics of NP uptake appear to be more complex in the soil compared to the plant aerial part. Several factors, as the presence of mucilage and exudates, symbiotic organisms, and soil organic matter may influence NPs availability. For instance, root mucilage and exudates normally excreted into the rhizosphere play a dual role: they may promote NP adhesion to the root surface, which in turn may enhance NP internalization rate or, conversely, these gel-like substances may also trigger NP trapping and aggregation (Avellan et al., 2017; Milewska-Hendel et al., 2017). Recent observations, by means of X-ray computed nanotomography and enhanced dark-field microscopy combined with hyperspectral imaging, have demonstrated that root border cells and associated mucilage tend to trap gold NPs irrespective of particle charge, 
while negatively charged NPs are not sequestered by the mucilage of Arabidopsis thaliana root cap and translocate directly into the root tissue (Avellan et al., 2017).

The presence of symbiotic bacteria and fungi in the soil have been demonstrated to play controversial roles as well; in general, they enhance accumulation of different types of heavy metal NPs in true grasses, but reduce nano-Ag and nano-FeO uptake in legumes (Whiteside et al., 2009; Feng et al., 2013; Guo and Chi, 2014).

\section{Nanoparticle Mobilization in Plant}

Once penetrated the plant outer protective layers and regardless of aerial or hypogeal exposure, NMs have two mobilization routes in the plant: apoplastic and symplastic paths (Figure 1B). Apoplastic transport occurs outside the plasma membrane through the cell wall and extracellular spaces, whereas symplastic movements involve the transport of water and solutes between the cytoplasm of adjacent cells connected by plasmodesmata and sieve plate pores.

Apoplastic transport has been demonstrated to promote radial movement of NMs, which may move NPs to the root central cylinder and the vascular tissues, and promoting their movement upwards the aerial part (González-Melendi et al., 2008; Larue et al., 2014; Sun et al., 2014; Zhao et al., 2017). This manner of NP translocation is instrumental for applications requiring systemic NP delivery. However, the Casparian strip, a longitudinally oriented layer made of lignin-like structures, prevent the completion of this radial movement in the root endodermis (Sun et al., 2014; Lv et al., 2015). To bypass this natural barrier, water and another solute switch from apoplastic to the simplastic path. Similar abilities to circumvent the block at Casparian strip have been documented for different kinds of NPs as reviewed in Schwab et al. (2016). This may happen especially in those anatomical regions where the Casparian strip is not yet properly formed, such as root tips and root lateral junctions (Lv et al., 2019).

The symplastic transport of NPs requires that at some point NPs penetrate inside the cells. The presence of a rigid plant cell wall creates a physical barrier to the cell entry and makes the intracellular delivery of NPs in plants much more difficult with respect to animal cells. Basically, the cell wall is a multi-layered framework of primarily cellulose/hemicellulose microfibrils and scaffold proteins, creating a porous milieu which acts as a narrow selective filter with a mean diameter $<10 \mathrm{~nm}$, with some exception up to $20 \mathrm{~nm}$ (Carpita et al., 1979). Actually, this is a critical point and currently represents one of the main hurdles to the design and the implementation of bioengineering tools in plants (Cunningham et al., 2018). However, different types of nanoparticles with a mean diameter between 3 and $50 \mathrm{~nm}$ and carbon nanotubes have been demonstrated to easily pass through the cell wall in many plant species (Liu et al., 2009; Kurepa et al., 2010; Chang et al., 2013; Etxeberria et al., 2019).

Subsequent cell internalization may occur preferentially by endocytosis (Valletta et al., 2014; Palocci et al., 2017), although alternative cell entry mechanisms, such as those based on pore formation, membrane translocation or carrier proteins already described in cells (Nel et al., 2009; Lin et al., 2010; Wang et al.,
2012) and in invertebrate models (Marchesano et al., 2013) need to be further elucidated in plant cells. For instance, it has been demonstrated that Multi-Walled Carbon nanotubes (MWCNTs) may enter in Catharanthus roseus protoplasts by an endosomeescaping uptake mode (Serag et al., 2011).

Once in the cytoplasm, cell to cell movements of NPs are facilitated by plasmodesmata, membrane-lined cytoplasmic bridges with a flexible diameter $(20-50 \mathrm{~nm})$, which ensure membrane and cytoplasmic continuity among cells throughout plant tissues. Transport of NPs with variable sizes through plasmodesmata has been described in Arabidopsis, rice, and poplar plant species (Lin et al., 2009; Geisler-Lee et al., 2013; Zhai et al., 2014).

Through the symplastic and apoplastic pathways, small particles can reach the xylem and phloem vessels and translocate in the whole plant to different tissues and organs. Remarkably, organs like flowers, fruits and seeds normally have a strong capability to import fluids from the phloem (sink activity) and tend to accumulate NMs. Besides plant toxicity, NP accumulation in specialized organs raises another important issue related to their safe use in human and animal consumption (Pérez-de-Luque, 2017).

Worth mentioning from an application perspective, studies in different crops, such as maize, spinach, cabbage, reported the ability of metal-NPs to penetrate seeds and translocate into the seedlings, without significant effects on seed viability, germination rate, and shoot development. These data suggest the possible use of functional NPs for seed priming and plant growth stimulation, also in limiting environmental conditions (Zheng et al., 2005; Răcuciu and Creangă, 2009; Pokhrel and Dubey, 2013).

\section{Nanoparticle Phytotoxicity}

The comprehension of NM toxicity in crop plants is still at dawn, but it is crucial for the implementation of innovative agronanotech tools and products (Servin and White, 2016). Current NP studies in plants have investigated unrealistic scenarios, such as short-term and high dose exposure, often in model media and plant species, gathering contradictory results (Miralles et al., 2012). Basically, most of the studies have demonstrated that in cultivated species (e.g., tomato, wheat, onion, and zucchini) excess of metal-based NPs trigger an oxidative burst by interfering with the electron transport chain as well as by impairing the reactive oxygen species (ROS) detoxifying machinery, with genotoxic implications (Dimkpa et al., 2013; Faisal et al., 2013; Pakrashi et al., 2014; Pagano et al., 2016). As a consequence, plant secondary metabolism, hormonal balance and growth are often negatively affected. Interestingly, recent transcriptome analyses revealed that exposures to different types of NPs (e.g., zinc oxide, fullerene soot, or titanium dioxide) exposure represses a significant number of genes involved in phosphate-starvation, pathogen and stress responses, with possible negative effects on plant root development and defense mechanisms in A. thaliana. A recent systems biology approach, including omics data from tobacco, rice, rocket salad, wheat, and kidney beans, confirmed that metal NMs provoke a generalized stress response, with the prevalence of oxidative 
stress components (Ruotolo et al., 2018). These data suggest that further studies based on high-throughput analysis of genetic and metabolic responses, triggered by NP exposure, are necessary to shed light on many aspects of NP phytotoxicity in crops, even in absence of overt toxicity at the phenotypic level (Majumdar et al., 2015). In light of these evidence, it appears fair to exploit for future applications in plants engineered NMs for which a safe profile has been already established in animal systems, such as soft polymeric NPs.

\section{CURRENT APPLICATIONS IN PLANT SCIENCE}

As mentioned above, while nanotechnology innovation is running fast in many fields of life science, smart applications in plant and agricultural science still lag behind (Wang et al., 2016). In this section, we review the most significant current approaches (schematized in Figure 1C), in particular, those inherent to biosensing, delivery of agrochemicals and genetic engineering. Representative applications for different types of NPs are also listed in Table 1 together with a brief description of their positive effects and drawbacks in plant species.

\section{Biosensors}

NMs have been applied to develop biosensors or they have been used as "sensing materials" in the fields of crop biotechnology, agriculture, and food industry (Duhan et al., 2017; Chaudhry et al., 2018). Different categories of nanosensor types have been tested in plants, including plasmonic nanosensors, fluorescence resonance energy transfer (FRET)-based nanosensors, carbonbased electrochemical nanosensors, nanowire nanosensors and antibody nanosensors. Although the use of nanosensors in plants is at an initial stage (Rai et al., 2012), interesting reports have proposed the use of NMs as tools for detection and quantification of plant metabolic flux, residual of pesticides in food and bacteria, viral and fungal pathogens. Recently, it has been reported the fabrication of a fluorometric optical onion membrane-based sensor for detection of sucrose based on the synthesis of invertase-nanogold clusters embedded in plant membranes (Bagal-Kestwal et al., 2015). In addition, singlewalled carbon nanotubes (SWNTs) have been exploited for nearinfrared fluorescence monitoring of nitric oxide in A. thaliana (Giraldo et al., 2014). FRET probes conjugated to polystyrene NPs have been also designed to quantify and recognize the phytoalexins (Dumbrepatil et al., 2010).

As above mentioned, NMs-based biosensors are very promising as they allow rapid detection and precise quantification of fungi, bacteria and viruses in plants (Duhan et al., 2017). For example, fluorescent silica NPs combined with antibody was designed for diagnosing Xanthomonas axonopodis pv. vesicatoria, which causes bacterial spot disease in Solanaceae plants (Yao et al., 2009). Recently, Au NPs have been proposed from Lau et al. as DNA biochemical labels to detect Pseudomonas syringae in A. thaliana by differential pulse voltammetry (DPV) on disposable screen-printed carbon electrodes (Lau et al., 2017). Similarly, fluorescently labeled-DNA oligonucleotide conjugated to Au NPs were employed in the diagnosis of the phytoplasma associated with the flavescence dorée disease of grapevine (Firrao et al., 2005). Finally, smart nanosensors are also available for mycotoxin detection; for instance, the 4 mycosensor is a competitive antibody-based assay successfully introduced in the market to test the presence of ZEA, T-2/HT-2, DON, and FB1/FB2 mycotoxin residues in corn, wheat, oat and barley (Lattanzio and Nivarlet, 2017).

\section{Controlled Release of Agrochemicals and Nutrients}

NMs can be applied to the soil as nanostructured fertilizers (nanofertilizers, as for $\mathrm{Fe}, \mathrm{Mn}, \mathrm{Zn}, \mathrm{Cu}, \mathrm{Mo} \mathrm{NPs}$ ) or can be used as enhanced delivery systems to improve the uptake and the performance of conventional fertilizers (nutrients and phosphates) (Liu and Lal, 2015). Even though nanofertilizers and NM-enhanced fertilizers are very promising for agriculture, the use of nanotechnology in fertilizer supply is very scanty (DeRosa et al., 2010).

Hydroxyapatite nanoparticles, used as phosphorous nanofertilizers, enhance the soybean growth rate and seed yield by 33 and $20 \%$, compared to a regular P fertilizer (Liu and Lal, 2015). In addition, nanofertilizers can be released at slower rates which may contribute to maintain the soil fertility by reducing the transport of these nutrients into a runoff or ground water and decreasing the risks of environmental pollution and toxic effects due to their over-application (Liu and Lal, 2015).

Metallic nanoparticles based on Iron oxide, $\mathrm{ZnO}, \mathrm{TiO}_{2}$, and copper have been directly applied as nanofertilizers in soil by irrigation or via foliar applications in different plants, such as mung bean plant, cucumber and rape (Gao et al., 2006; Tarafdar et al., 2014; Saharan et al., 2016; Verma et al., 2018). Similarly, MWNTs used as soil supplements increased twice the number of flowers and fruits in tomato plants likely through the activation of genes/proteins essential for plant growth and development (Khodakovskaya et al., 2013). Despite these intriguing evidence, the use of nanofertilizers is still debatable. Accumulation in treated soils may pose a threat to soil microbial communities such as small invertebrates, bacteria and fungi (Frenk et al., 2013; Waalewijn-Kool et al., 2013; Shen et al., 2015; Simonin et al., 2016; Goncalves et al., 2017). This impact on the agro-ecosystem reasonably discourages the use of metallic nanoparticles in agriculture.

Only recently, a natural polymer, such as chitosan NPs, have been used for controlled release of nitrogen, phosphorus and potassium in wheat by foliar uptake (Abdel-Aziz et al., 2016). The use of organic NPs is more acceptable in terms of environmental pollution. However, their effective advantages for nutrient supply over traditional fertilization methods need more robust evidence (Liu and Lal, 2015).

On the other hand, pesticides delivered by nanomaterials generally have increased stability and solubility and enable slow release and effective targeted delivery in pest management (Duhan et al., 2017). Organic and polymeric NPs in the form of nanospheres or nanocapsules have been used as nanocarriers for herbicide distribution (Tanaka et al., 2012). In particular, 


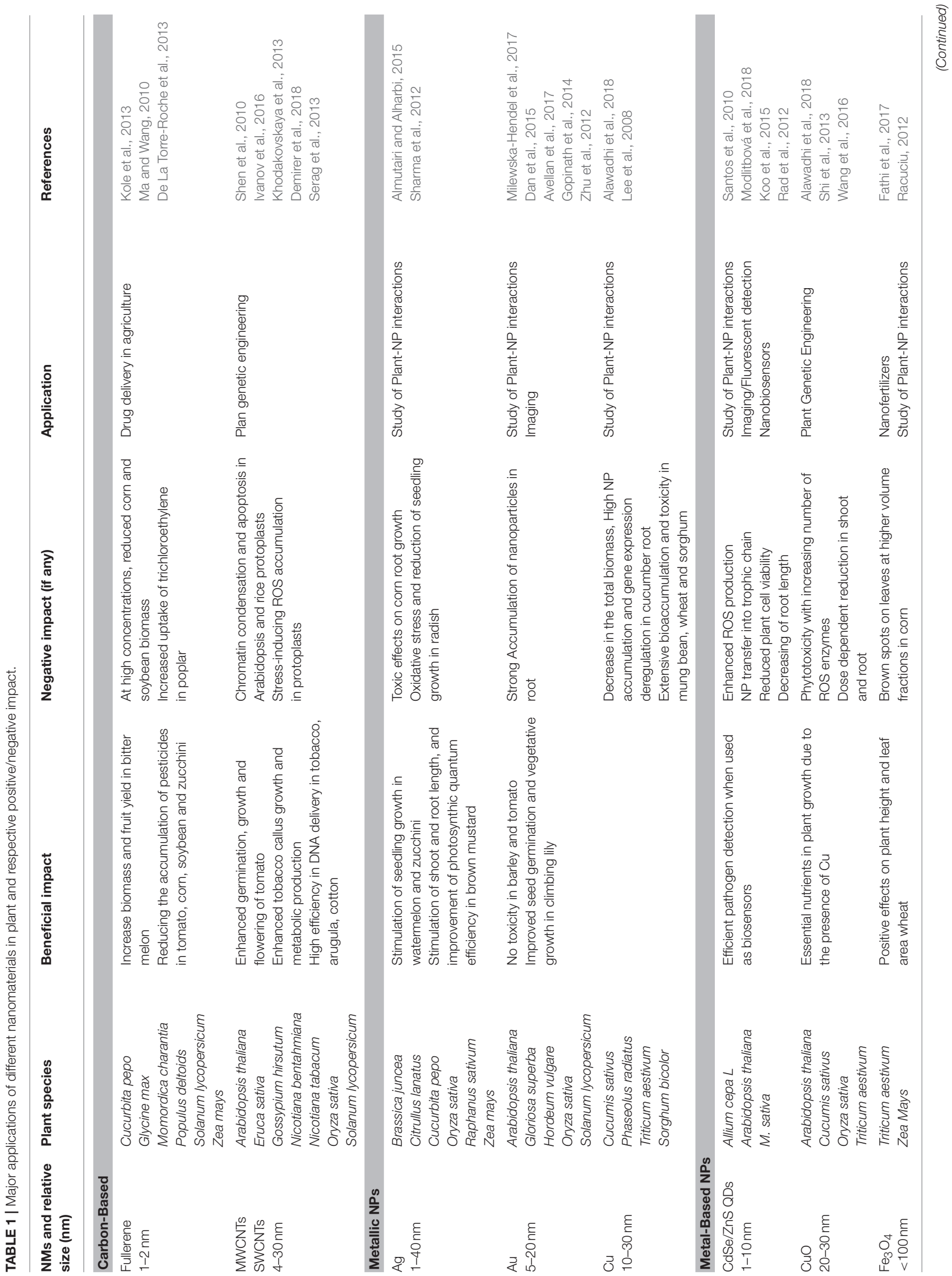




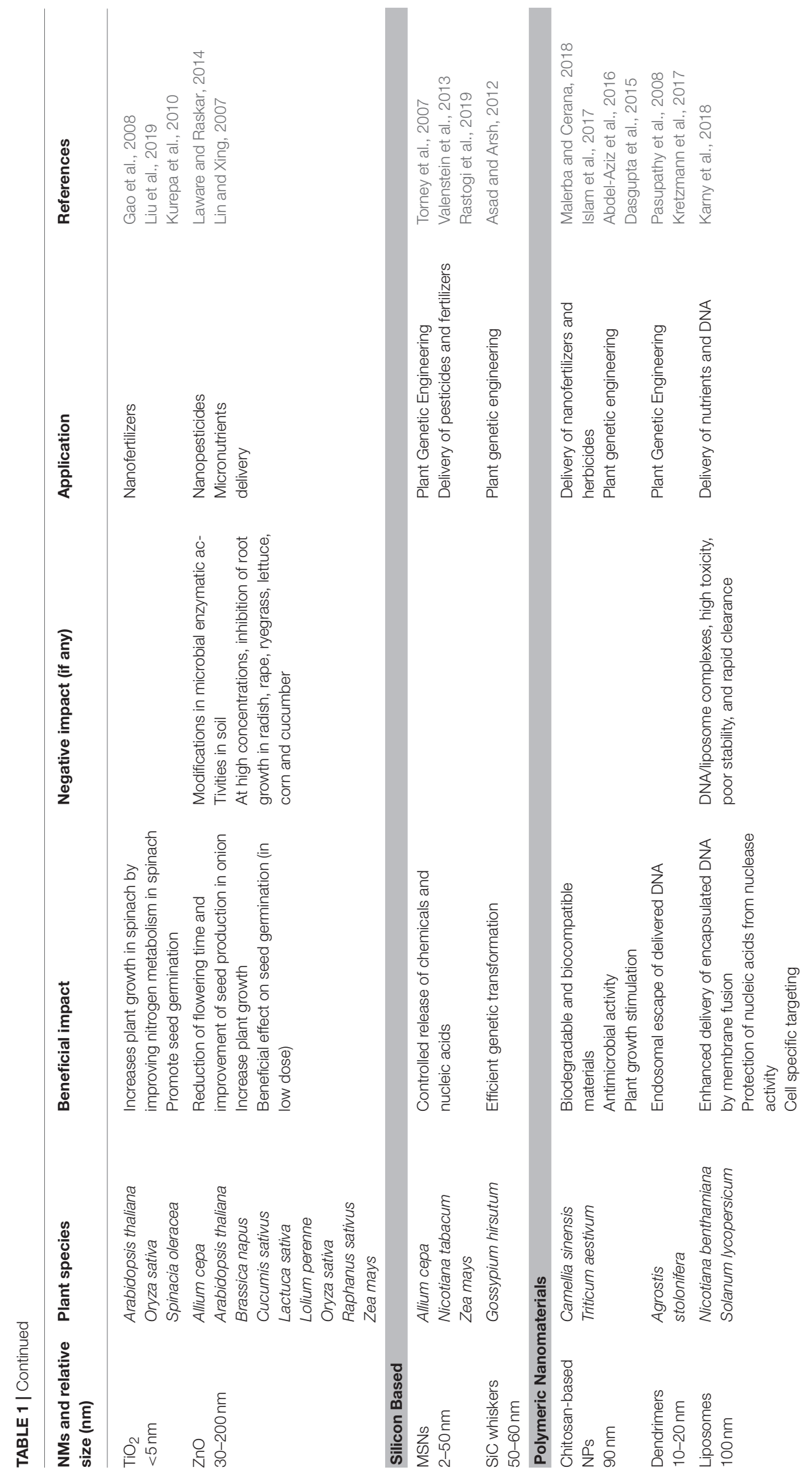


polymeric NPs, such as Poly(epsilon-caprolactone), present good properties of biocompatibility and have been repeatedly used for the encapsulation of atrazine herbicide (Tanaka et al., 2012). In another study, chitosan nanoparticles loaded with three triazine herbicides have shown reduced environmental impact and low genotoxic effects in Allium cepa (Grillo et al., 2015).

\section{Nanomaterials for Plant Genetic Engineering}

As stated above, the cell wall represents a barrier to the delivery of exogenous biomolecules in plant cells. To overcome this barrier and achieve plant genetic transformation, different strategies based on Agrobacterium transformation or biolistic methods are worldwide used for DNA delivery in plant cells. Limitations to these approaches rely on narrow host range and plant extensive damages, which often inhibit plant development.

Most of the pioneering studies for nanomaterial-based plant genetic engineering have been conducted in plant cell cultures. For example, Silicon Carbide-Mediated Transformation has been reported as a successful approach to deliver DNA in different calli (tobacco, maize, rice, soybean and cotton) (Armstrong and Green, 1985; Wang et al., 1995; Serik et al., 1996; Asad and Arsh, 2012; Lau et al., 2017).

Although lagged behind the advancements achieved in animal systems, results reported recently in plants are proving that NMs may overcome the barrier of the cell wall in adult plants and reduce the drawbacks associated with current transgene delivery systems.

One seminal study proved that dsRNA of different plant viruses can be loaded on non-toxic, degradable, layered double hydroxide (LDH) clay nanosheets or BioClay. The dsRNAs and/or their RNA breakdown products provide protection against the Cauliflower Mosaic Virus (CMV) in sprayed tobacco leaves, but they also confer systemic protection to newly emerged, unsprayed leaves on viral challenge 20 days after a single spray treatment in tobacco (Mitter et al., 2017). More in general, this is a proof of concept for species-independent and passive delivery of genetic material, without transgene integration, into plant cells for different biotechnology applications in plants.

A successful stable genetic transformation has been achieved in cotton plants via magnetic nanoparticles (MNPs). $\beta$ glucuronidase (GUS) reporter gene- MNP complex were infiltrated into cotton pollen grains by magnetic force, without compromising pollen viability. Through pollination with magnetofected pollen, cotton transgenic plants were successfully generated and exogenous DNA was successfully integrated into the genome, effectively expressed, and stably inherited in the offspring obtained by selfing (Zhao et al., 2017).

In another recent paper, carbon nanotubes scaffolds applied to external plant tissue by infusion were used to deliver linear and plasmid DNA, as well as siRNA, in Nicotiana benthamiana, Eruca sativa, Triticum aestivum, and Gossypium hirsutum leaves and in E. sativa protoplasts, resulting in a strong transient Green Fluorescent Protein (GFP) expression. Moreover, the same authors reported that small interfering RNA (siRNA) was delivered to $N$. benthamiana plants constitutively expressing GFP, causing a 95\% silencing of this gene (Demirer et al., 2018).

The first and promising approach of genome editing mediated by mesoporous silica nanoparticles (MSNs) has been recently proposed. MSNs have used as carriers to deliver Cre recombinase in Zea mays immature embryos, carrying loxP sites integrated into chromosomal DNA. After the biolistic introduction of engineered MSNs in plant tissues, the loxP was correctly recombined establishing a successful genome editing (Valenstein et al., 2013).

\section{CONCLUSIONS AND FUTURE PERSPECTIVES}

Herein, we have discussed various facets of using NMs in plant sciences. In the last years, it has been demonstrated that nanotechnology has made huge progress in the synthesis of NMs and their application in medicine for diagnosis and therapy. On the other side, the application of NMs for plants is still poor. Recent outcomes and current applications suggest that more studies are necessary for this direction to optimize the synthesis and biofunctionalization of NMs for plant applications, but also to elucidate deeper the mechanisms of plant uptake and improving the sustainability for agro-ecosystems and human health. Interestingly, applications need to be extended to address uncovered important aspects of plant physiology. For instance, nanobiosensors for detecting secondary metabolites or phytoregulators in real time may provide advances in monitoring plant development and interactions with the environment, especially in limiting growth conditions.

Despite the huge progress in plant genetics, the delivery of exogenous DNA and/or enzymes for genome editing remain a big challenge. New strategies based on nanoparticlemediated clustered regularly interspersed palindromic repeatsCRISPR associated proteins (CRISPR-Cas9) technology, as those tested in other biological systems (Lee et al., 2017; Glass et al., 2018), would provide ground-breaking innovation in plant genetics.

On the base of consolidated evidence reported in cell and animal models, soft materials, like nanogels, and polymeric nanostructures should be further exploited as favorable candidates to develop new strategies for controlled release of biomolecules and plant genome editing. Owing to their safe profile, high loading capacity and excellent cargo protection from degradation polymeric and hydrogel-based NPs have shown undeniable advantages in drug delivery. Moreover, this kind of NMs has been elegantly employed to achieve a controlled (spatial and temporal) release of cargos triggered by external stimuli (e.g., UV, NIR, acoustic waves etc.) (Ma et al., 2013; Ambrosone et al., 2016; Linsley and Wu, 2017) in cell and animal models. These outstanding results suggest that the huge potential of soft nanomaterials remains almost unexplored in plants. Besides a few successful attempts for agrochemicals delivery above-mentioned and listed in Table $\mathbf{1}$, more efforts are needed to design strategies and smart tools based on polymeric or hybrid materials for applications in plants. Of course, a careful analysis 
of manufacturing scalability and cost-effectiveness needs to be undertaken before the extensive use of polymeric nanomaterials in agriculture.

As a final remark, the delay in plant nanotechnology might be overcome by encouraging the activation of multidisciplinary approaches for the design and the synthesis of smart nanomaterials. To this aim, joint collaborative initiatives, merging complementary professional competencies such those

\section{REFERENCES}

Abdel-Aziz, H. M. M., Hasaneen, M. N. A., and Omer, A. M. (2016). Nano chitosan-NPK fertilizer enhances the growth and productivity of wheat plants grown in sandy soil. Spanish J. Agric. Res. 14, 1-9. doi: 10.5424/sjar/2016141-8205

Abedini, A., Daud, A. R., Hamid, M. A. A., Othman, N. K., and Saion, E. (2013). A review on radiation-induced nucleation and growth of colloidal metallic nanoparticles. Nanoscale Res. Lett. 8, 1-10. doi: 10.1186/1556-276X-8-474

Alawadhi, H., Ramamoorthy, K., Mosa, K. A., Elnaggar, A., Ibrahim, E., El-Naggar, M., et al. (2018). Copper nanoparticles induced genotoxicty, oxidative stress, and changes in Superoxide Dismutase (SOD) gene expression in cucumber (Cucumis sativus) plants. Front. Plant Sci. 9:872. doi: 10.3389/fpls.2018.00872

Almutairi, Z. M., and Alharbi, A. (2015). Effect of silver nanoparticles on seed germination of crop plants. Int. J. Biol. Biomol. Agric. Food Biotechnol. Eng. 9, 572-576. doi: 10.24297/jaa.v4i1.4295

Al-Salim, N., Barraclough, E., Burgess, E., Clothier, B., Deurer, M., Green, S., et al. (2011). Quantum dot transport in soil, plants, and insects. Sci. Total Environ. 409:3237-3248.doi: 10.1016/j.scitotenv.2011.05.017

Ambrosone, A., Marchesano, V., Carregal-Romero, S., Intartaglia, D., Parak, W. J., and Tortiglione, C. (2016). Control of Wnt/ $\beta$-catenin signaling pathway in vivo via light responsive capsules. ACS Nano 10, 4828-4834. doi: 10.1021/acsnano.5b07817

Armstrong, C. L., and Green, C. E. (1985). Establishment and maintenance of friable, embryogenic maize callus and the involvement of L-proline. Planta 164:207-214. doi: 10.1007/BF00396083

Asad, S., and Arsh, M. (2012). "Silicon carbide whisker-mediated plant transformation," in Properties and Applications of Silicon Carbide, ed R. Gerhardt (Rijeka: BoD-Books on Deman), 1-16. doi: 10.5772/15721

Astm E2456 - 06 (2012). (2006)Standard Terminol. Relat. to Nanotechnol. 06, 5-6. doi: 10.1520/E2456-06R12

Avellan, A., Schwab, F., Masion, A., Chaurand, P., Borschneck, D., Vidal, V., et al. (2017). Nanoparticle uptake in plants: gold nanomaterial localized in roots of Arabidopsis thaliana by X-ray computed nanotomography and hyperspectral imaging. Environ. Sci. Technol. 51, 8682-8691. doi: 10.1021/acs.est.7b01133

Bagal-Kestwal, D., Kestwal, R. M., and Chiang, B. H. (2015). Invertase-nanogold clusters decorated plant membranes for fluorescence-based sucrose sensor. J. Nanobiotechnology 13:30. doi: 10.1186/s12951-015-0089-1

Baskar, V., Meeran, S., Shabeer, S., T. K., Subramani, Sruthi, and Ali, J. (2018). Historic review on modern herbal nanogel formulation and delivery methods. Int. J. Pharm. Pharm. Sci. 10, 1-10. doi: 10.22159/ijpps.2018v10i10.23071

Bruchez, M., Moronne, M., Gin, P., Weiss, S., and Alivisatos, A. P. (1998). Semiconductor nanocrystals as fluorescent biological labels. Science 281, 2013-2016. doi: 10.1126/science.281.5385.2013

Carpita, N., Sabularse, D., Montezinos, D., and Delmer, D. P. (1979). Determination of the pore size of cell walls of living plant cells. Science 205, 1144-1147. doi: 10.1126/science.205.4411.1144

Chang, F. P., Kuang, L. Y., Huang, C. A., Jane, W. N., Hung, Y., Hsing, Y. I. C., et al. (2013). A simple plant gene delivery system using mesoporous silica nanoparticles as carriers. J. Mater. Chem. B 1, 5279-5287. doi: $10.1039 / \mathrm{c} 3 \mathrm{tb} 20529 \mathrm{k}$

Chaudhry, N., Dwivedi, S., Chaudhry, V., Singh, A., Saquib, Q., Azam, A., et al. (2018). Bio-inspired nanomaterials in agriculture and food: current status, foreseen applications and challenges. Microb. Pathog. 123, 196-200. doi: 10.1016/j.micpath.2018.07.013 of plant biologists, geneticists, chemists, biochemists, and engineers, may disclose new horizons in phytonanotechnology.

\section{AUTHOR CONTRIBUTIONS}

IS and AA conceived the idea and organized this mini review. All authors wrote the manuscript and approved the contents for publication.

Chichiriccò, G., and Poma, A. (2015). Penetration and toxicity of nanomaterials in higher plants. Nanomaterials 5, 851-873. doi: 10.3390/nano5020851

Cunningham, F. J., Goh, N. S., Demirer, G. S., Matos, J. L., and Landry, M. P. (2018). Nanoparticle-mediated delivery towards advancing plant genetic engineering. Trends Biotechnol. 36, 882-897. doi: 10.1016/j.tibtech.2018.03.009

Dan, Y., Zhang, W., Xue, R., Ma, X., Stephan, C., and Shi, H. (2015) Characterization of gold nanoparticle uptake by tomato plants using enzymatic extraction followed by single-particle inductively coupled plasma-mass spectrometry analysis. Environ. Sci. Technol. 49, 3007-3014. doi: 10.1021/es506179e

Dasgupta, A., Chakraborty, N., Panda, K., Chandra, S., Acharya, K., and Sarkar, J. (2015). Chitosan nanoparticles: a positive modulator of innate immune responses in plants. Sci. Rep. 5:15195. doi: 10.1038/srep15195

De La Torre-Roche, R., Hawthorne, J., Deng, Y., Xing, B., Cai, W., Newman, L. A., et al. (2013). Multiwalled carbon nanotubes and C60 fullerenes differentially impact the accumulation of weathered pesticides in four agricultural plants. Environ. Sci. Technol. 47, 12539-12547. doi: 10.1021/es4034809

Demirer, G. S., Zhang, H., Matos, J., Goh, N., Cunningham, F. J., Sung, Y., et al. (2018). High aspect ratio nanomaterials enable delivery of functional genetic material without DNA integration in mature plants. bioRxiv 10, 1-32. doi: 10.1101/179549

DeRosa, M. C., Monreal, C., Schnitzer, M., Walsh, R., and Sultan, Y. (2010). Nanotechnology in fertilizers. Nat. Nanotechnol. 5, 91-91. doi: $10.1038 /$ nnano.2010.2

Dimkpa, C. O., McLean, J. E., Martineau, N., Britt, D. W., Haverkamp, R., and Anderson, A. J. (2013). Silver nanoparticles disrupt wheat (Triticum aestivum L.) growth in a sand matrix. Environ. Sci. Technol. 47, 1082-1090. doi: 10.1021/es302973y

Duhan, J. S., Kumar, R., Kumar, N., Kaur, P., Nehra, K., and Duhan, S. (2017) Nanotechnology: the new perspective in precision agriculture. Biotechnol. Rep. 15, 11-23. doi: 10.1016/j.btre.2017.03.002

Dumbrepatil, A. B., Lee, S. G., Chung, S. J., Lee, M. G., Park, B. C., Kim, T. J., et al. (2010). Development of a nanoparticle-based FRET sensor for ultrasensitive detection of phytoestrogen compounds. Analyst 135, 2879-2886. doi: 10.1039/c0an00385a

Eichert, T., Kurtz, A., Steiner, U., and Goldbach, H. E. (2008). Size exclusion limits and lateral heterogeneity of the stomatal foliar uptake pathway for aqueous solutes and water-suspended nanoparticles. Physiol. Plant. 134, 151-160. doi: 10.1111/j.1399-3054.2008.01135.x

Etxeberria, E., Gonzalez, P., Bhattacharya, P., Sharma, P., and Ke, P. C. (2019). Determining the size exclusion for nanoparticles in citrus leaves. Hort Sci. 51, 732-737. doi: 10.21273/HORTSCI.51.6.732

Faisal, M., Saquib, Q., Alatar, A. A., Al-Khedhairy, A. A., Hegazy, A. K., and Musarrat, J. (2013). Phytotoxic hazards of NiO-nanoparticles in tomato: a study on mechanism of cell death. J. Hazard. Mater. 250-251, 318-332. doi: 10.1016/j.jhazmat.2013.01.063

Fathi, A., Zahedi, M., Torabian, S., and Khoshgoftar, A. (2017). Response of wheat genotypes to foliar spray of $\mathrm{ZnO}$ and $\mathrm{Fe} 2 \mathrm{O} 3$ nanoparticles under salt stress. J. Plant Nutr. 40, 1376-1385. doi: 10.1080/01904167.2016.1262418

Feng, Y., Cui, X., He, S., Dong, G., Chen, M., Wang, J., et al. (2013). The role of metal nanoparticles in influencing arbuscular mycorrhizal fungi effects on plant growth. Environ. Sci. Technol. 47, 9496-9504. doi: 10.1021/es402109n

Firrao, G., Moretti, M., Ruiz Rosquete, M., Gobbi, E., and Locci, R. (2005). Nanobiotransducer for detecting flavescence dorée phytoplasma. J. Plant Pathol. 87, 101-107. doi: 10.4454/jpp.v87i2.903 
Frenk, S., Ben-Moshe, T., Dror, I., Berkowitz, B., and Minz, D. (2013). Effect of metal oxide nanoparticles on microbial community structure and function in two different soil types. PLOS ONE 8:e84441. doi: 10.1371/journal.pone. 0084441

Gao, F., Hong, F., Liu, C., Zheng, L., Su, M., Wu, X., et al. (2006). Mechanism of nano-anatase $\mathrm{TiO} 2$ on promoting photosynthetic carbon reaction of spinach: inducing complex of Rubisco-Rubisco activase. Biol. Trace Elem. Res. 111, 239-253. doi: 10.1385/BTER:111:1:239

Gao, F., Liu, C., Qu, C., Zheng, L., Yang, F., Su, M., et al. (2008). Was improvement of spinach growth by nano- $\mathrm{TiO} 2$ treatment related to the changes of Rubisco activase? BioMetals 21, 211-217. doi: 10.1007/s10534-007-9110-y

García-Gómez, C., Obrador, A., González, D., Babín, M., and Fernández, M. D. (2018). Comparative study of the phytotoxicity of $\mathrm{ZnO}$ nanoparticles and $\mathrm{Zn}$ accumulation in nine crops grown in a calcareous soil and an acidic soil. Sci. Total Environ. 644, 770-780. doi: 10.1016/j.scitotenv.2018.06.356

Geisler-Lee, J., Wang, Q., Yao, Y., Zhang, W., Geisler, M., Li, K., et al. (2013). Phytotoxicity, accumulation and transport of silver nanoparticles by Arabidopsis thaliana. Nanotoxicology 7, 323-337. doi: 10.3109/17435390.2012.658094

Ghosh Chaudhuri, R., and Paria, S. (2012). Core/shell nanoparticles: classes, properties, synthesis mechanisms, characterization, and applications. Chem. Rev. 112, 2373-2433. doi: 10.1021/cr100449n

Giraldo, J. P., Landry, M. P., Faltermeier, S. M., McNicholas, T. P., Iverson, N. M., Boghossian, A. A., et al. (2014). Plant nanobionics approach to augment photosynthesis and biochemical sensing. Nat. Mater. 13, 400-408. doi: $10.1038 /$ nmat3890

Glass, Z., Lee, M., Li, Y., and Xu, Q. (2018). Engineering the delivery system for CRISPR-based genome editing. Trends Biotechnol. 36, 173-185. doi: 10.1016/j.tibtech.2017.11.006

Goncalves, M. F. M., Gomes, S. I. L., Scott-Fordsmand, J. J., and Amorim, M. J. B. (2017). Shorter lifetime of a soil invertebrate species when exposed to copper oxide nanoparticles in a full lifespan exposure test. Sci. Rep. 7:1355. doi: 10.1038/s41598-017-01507-8

González-Melendi, P., Fernández-Pacheco, R., Coronado, M. J., Corredor, E., Testillano, P. S., Risueño, M. C., et al. (2008). Nanoparticles as smart treatment-delivery systems in plants: assessment of different techniques of microscopy for their visualization in plant tissues. Ann. Bot. 101, 187-195. doi: $10.1093 / \mathrm{aob} / \mathrm{mcm} 283$

Gopinath, K., Gowri, S., Karthika, V., and Arumugam, A. (2014). Green synthesis of gold nanoparticles from fruit extract of Terminalia arjuna, for the enhanced seed germination activity of Gloriosa superba. J. Nanostructure Chem. 4:115. doi: 10.1007/s40097-014-0115-0

Grillo, R., Clemente, Z., Oliveira, J. L., de Campos, E. V. R., Chalupe, V. C., Jonsson, C. M., et al. (2015). Chitosan nanoparticles loaded the herbicide paraquat: the influence of the aquatic humic substances on the colloidal stability and toxicity. J. Hazard. Mater. 286, 562-572. doi: 10.1016/j.jhazmat.2014.12.021

Guo, J., and Chi, J. (2014). Effect of Cd-tolerant plant growth-promoting rhizobium on plant growth and Cd uptake by Lolium multiflorum Lam. and Glycine $\max ($ L.) Merr. in Cd-contaminated soil. Plant Soil 375, 205-214. doi: 10.1007/s11104-013-1952-1

Islam, P., Water, J. J., Bohr, A., and Rantanen, J. (2017). Chitosan-based nanoembedded microparticles: impact of Nanogel composition on physicochemical properties. Pharmaceutics 9, 1-12. doi: 10.3390/pharmaceutics9010001

Ivanov, I., Khodakovskaya, M., Dervishi, E., Lahiani, M. H., and Chen, J. (2016). Comparative study of plant responses to carbon-based nanomaterials with different morphologies. Nanotechnology 27:265102. doi: 10.1088/0957-4484/27/26/265102

Jahan, S., Alias, Y. B., Bakar, A. F. B. A., and Yusoff, I. B. (2018). Toxicity evaluation of $\mathrm{ZnO}$ and $\mathrm{TiO} 2$ nanomaterials in hydroponic red bean (Vigna angularis) plant: physiology, biochemistry and kinetic transport. J. Environ. Sci. 72, 140-152. doi: 10.1016/j.jes.2017.12.022

Jeevanandam, J., Barhoum, A., Chan, Y. S., Dufresne, A., and Danquah, M. K. (2018). Review on nanoparticles and nanostructured materials: history, sources, toxicity and regulations. Beilstein J. Nanotechnol. 9, 1050-1074. doi: 10.3762/bjnano.9.98

Karny, A., Zinger, A., Kajal, A., Shainsky-Roitman, J., and Schroeder, A. (2018). Therapeutic nanoparticles penetrate leaves and deliver nutrients to agricultural crops. Sci. Rep. 8:7589. doi: 10.1038/s41598-018-25197-y
Khan, M. N., Mobin, M., Abbas, Z. K., AlMutairi, K. A., and Siddiqui, Z. H. (2017). Role of nanomaterials in plants under challenging environments. Plant Physiol. Biochem. 110, 194-209. doi: 10.1016/j.plaphy.2016.05.038

Khodakovskaya, M. V., Kim, B. S., Kim, J. N., Alimohammadi, M., Dervishi, E., Mustafa, T., et al. (2013). Carbon nanotubes as plant growth regulators: effects on tomato growth, reproductive system, and soil microbial community. Small 9, 115-123. doi: 10.1002/smll.201201225

Kole, C., Kole, P., Randunu, K. M., Choudhary, P., Podila, R., Ke, P. C., et al. (2013). Nanobiotechnology can boost crop production and quality: first evidence from increased plant biomass, fruit yield and phytomedicine content in bitter melon (Momordica charantia). BMC Biotechnol. 13:37. doi: 10.1186/1472-6750-13-37

Koo, Y., Wang, J., Zhang, Q., Zhu, H., Chehab, E. W., Colvin, V. L., et al. (2015). Fluorescence reports intact quantum dot uptake into roots and translocation to leaves of arabidopsis thaliana and subsequent ingestion by insect herbivores. Environ. Sci. Technol. 49, 626-632. doi: 10.1021/es5050562

Kretzmann, J. A., Ho, D., Evans, C. W., Plani-Lam, J. H. C., Garcia-Bloj, B., Mohamed, A. E., et al. (2017). Synthetically controlling dendrimer flexibility improves delivery of large plasmid DNA. Chem. Sci. 8, 2923-2930. doi: 10.1039/C7SC00097A

Kurepa, J., Paunesku, T., Vogt, S., Arora, H., Rabatic, B. M., Lu, J., et al. (2010). Uptake and distribution of ultrasmall anatase $\mathrm{TiO} 2$ alizarin red s nanoconjugates in arabidopsis thaliana. Nano Lett. 10, 2296-2302. doi: $10.1021 / \mathrm{nl} 903518 \mathrm{f}$

Larue, C., Castillo-Michel, H., Sobanska, S., Cécillon, L., Bureau, S., Barthès, V., et al. (2014). Foliar exposure of the crop Lactuca sativa to silver nanoparticles: evidence for internalization and changes in Ag speciation. J. Hazard. Mater. 264, 98-106. doi: 10.1016/j.jhazmat.2013.10.053

Lattanzio, V. M. T., and Nivarlet, N. (2017). Multiplex dipstick immunoassay for semiquantitative determination of fusarium mycotoxins in oat in Methods $\mathrm{Mol}$ Biol. 1536, 137-142. doi: 10.1007/978-1-4939-6682-0_10

Lau, H. Y., Wu, H., Wee, E. J. H., Trau, M., Wang, Y., and Botella, J. R. (2017). Specific and sensitive isothermal electrochemical biosensor for plant pathogen DNA detection with colloidal gold nanoparticles as probes. Sci. Rep. 7:38896. doi: $10.1038 /$ srep38896

Laware, S. L., and Raskar, S. (2014). Influence of zinc oxide nanoparticles on growth, flowering and seed productivity in onion. Int. J. Curr. Microbiol. App. Sci. 3, 874-881.

Lee, K., Conboy, M., Park, H. M., Jiang, F., Kim, H. J., Dewitt, M. A., et al. (2017). Nanoparticle delivery of Cas9 ribonucleoprotein and donor DNA in vivo induces homology-directed DNA repair. Nat. Biomed. Eng. 1, 889-901. doi: 10.1038/s41551-017-0137-2

Lee, W. M., An, Y.-J., Yoon, H., and Kweon, H.-S. (2008). Toxicity and bioavailability of copper nanoparticles to the terrestrial plants mung bean (Phaseolus radiatus) and wheat. Environ. Toxicol. Chem. 27, 1915-1921. doi: $10.1897 / 07-481.1$

Lin, D., and Xing, B. (2007). Phytotoxicity of nanoparticles: Inhibition of seed germination and root growth. Environ. Pollut. 150, 243-250. doi: 10.1016/j.envpol.2007.01.016

Lin, J., Zhang, H., Chen, Z., and Zheng, Y. (2010). Penetration of lipid membranes by gold nanoparticles: insights into cellular uptake, cytotoxicity, and their relationship. ACS Nano 4, 5421-5429. doi: 10.1021/nn1010792

Lin, S., Reppert, J., Hu, Q., Hudson, J. S., Reid, M. L., Ratnikova, T. A., et al. (2009). Uptake, translocation, and transmission of carbon nanomaterials in rice plants. Small 5, 1128-1132. doi: 10.1002/smll.200801556

Linsley, C. S., and Wu, B. M. (2017). Recent advances in lightresponsive on-demand drug-delivery systems. Ther. Deliv. 8, 89-107. doi: 10.4155/tde-2016-0060

Liu, J., Williams, P. C., Goodson, B. M., Geisler-Lee, J., Fakharifar, M., and Gemeinhardt, M. E. (2019). TiO2nanoparticles in irrigation water mitigate impacts of aged Agnanoparticles on soil microorganisms, Arabidopsis thalianaplants, and Eisenia fetida earthworms. Environ. Res. 172, 202-215. doi: 10.1016/j.envres.2019.02.010

Liu, Q., Chen, B., Wang, Q., Shi, X., Xiao, Z., Lin, J., et al. (2009). Carbon nanotubes as molecular transporters for walled plant cells. Nano Lett. 9, 1007-1010. doi: $10.1021 / \mathrm{nl} 803083 \mathrm{u}$

Liu, R., and Lal, R. (2015). Potentials of engineered nanoparticles as fertilizers for increasing agronomic productions. Sci. Total Environ. 514, 131-139. doi: 10.1016/j.scitotenv.2015.01.104 
Lv, J., Christie, P., and Zhang, S. (2019). Uptake, translocation, and transformation of metal-based nanoparticles in plants: recent advances and methodological challenges. Environ. Sci. Nano 6, 41-59. doi: 10.1039/C8EN00645H

Lv, J., Zhang, S., Luo, L., Zhang, J., Yang, K., and Christied, P. (2015). Accumulation, speciation and uptake pathway of $\mathrm{ZnO}$ nanoparticles in maize. Environ. Sci. Nano 2, 68-77. doi: 10.1039/C.4E. N.00064A

Ma, J., Du, L. F., Chen, M., Wang, H. H., Xing, L. X., Jing, L. F., et al. (2013). Drug-loaded nano-microcapsules delivery system mediated by ultrasoundtargeted microbubble destruction: a promising therapy method. Biomed. Rep. 1, 506-510. doi: 10.3892/br.2013.110

$\mathrm{Ma}, \mathrm{X}$., and Wang, C. (2010). Fullerene nanoparticles affect the fate and uptake of trichloroethylene in phytoremediation systems. Environ. Eng. Sci. 27, 989-992. doi: 10.1089/ees.2010.0141

Majumdar, S., Almeida, I. C., Arigi, E. A., Choi, H., VerBerkmoes, N. C., TrujilloReyes, J., et al. (2015). Environmental effects of nanoceria on seed production of common bean (Phaseolus vulgaris): a proteomic analysis. Environ. Sci. Technol. 49, 13283-13293. doi: 10.1021/acs.est.5b03452

Malerba, M., and Cerana, R. (2018). Recent advances of chitosan applications in plants. Polymers. 10, 1-10. doi: 10.3390/polym10020118

Marchesano, V., Hernandez, Y., Salvenmoser, W., Ambrosone, A., Tino, A., Hobmayer, B., et al. (2013). Imaging inward and outward trafficking of gold nanoparticles in whole animals. ACS Nano 7, 2431-2442. doi: $10.1021 / \mathrm{nn} 305747 \mathrm{e}$

Milewska-Hendel, A., Zubko, M., Karcz, J., Stróz, D., and Kurczynska, E. (2017). Fate of neutral-charged gold nanoparticles in the roots of the Hordeum vulgare L. cultivar Karat. Sci. Rep. 7:3014. doi: 10.1038/s41598-017-02965-w

Miralles, P., Church, T. L., and Harris, A. T. (2012). Toxicity, uptake, and translocation of engineered nanomaterials in vascular plants. Environ. Sci. Technol. 46, 9224-9239. doi: 10.1021/es202995d

Mitter, N., Worrall, E. A., Robinson, K. E., Li, P., Jain, R. G., Taochy, C., et al. (2017). Clay nanosheets for topical delivery of RNAi for sustained protection against plant viruses. Nat. Plants 3:16207. doi: 10.1038/nplants.2016.207

Modlitbová, P., Porízka, P., Novotný, K., Drbohlavová, J., Chamradová, I., Farka, Z., et al. (2018). Short-term assessment of cadmium toxicity and uptake from different types of Cd-based quantum dots in the model plant Allium cepa L. Ecotoxicol. Environ. Saf. 153, 23-31. doi: 10.1016/j.ecoenv.2018.01.044

Molina, M., Asadian-Birjand, M., Balach, J., Bergueiro, J., Miceli, E., and Calderón, M. (2015). Stimuli-responsive nanogel composites and their application in nanomedicine. Chem. Soc. Rev. 44, 6161-6186. doi: 10.1039/C5CS00199D

Moon, J. W., Phelps, T. J., Fitzgerald, C. L., Lind, R. F., Elkins, J. G., Jang, G. G., et al. (2016). Manufacturing demonstration of microbially mediated zinc sulfide nanoparticles in pilot-plant scale reactors. Appl. Microbiol. Biotechnol. 100, 7921-7931. doi: 10.1007/s00253-016-7556-y

Nath, S., Kaittanis, C., Tinkham, A., and Perez, J. M. (2008). Dextran-coated gold nanoparticles for the assessment of antimicrobial susceptibility. Anal. Chem. 80, 1033-1038. doi: 10.1021/ac701969u

Neamtu, I., Rusu, A. G., Diaconu, A., Nita, L. E., and Chiriac, A. P. (2017). Basic concepts and recent advances in nanogels as carriers for medical applications. Drug Deliv. 24, 539-557. doi: 10.1080/10717544.2016.1276232

Nel, A. E., Mädler, L., Velegol, D., Xia, T., Hoek, E. M. V., Somasundaran, P., et al. (2009). Understanding biophysicochemical interactions at the nano-bio interface. Nat. Mater. 8, 543-557. doi: 10.1038/nmat2442

Pagano, L., Servin, A. D., De La Torre-Roche, R., Mukherjee, A., Majumdar, S., Hawthorne, J., et al. (2016). Molecular response of crop plants to engineered nanomaterials. Environ. Sci. Technol. 50, 7198-7207. doi: 10.1021/acs.est.6b01816

Pakrashi, S., Jain, N., Dalai, S., Jayakumar, J., Chandrasekaran, P. T., Raichur, A. M., et al. (2014). In vivo genotoxicity assessment of titanium dioxide nanoparticles by Allium cepa root tip assay at high exposure concentrations. PLoS ONE 9:e98828. doi: 10.1371/journal.pone.0087789

Palocci, C., Valletta, A., Chronopoulou, L., Donati, L., Bramosanti, M., Brasili, E., et al. (2017). Endocytic pathways involved in PLGA nanoparticle uptake by grapevine cells and role of cell wall and membrane in size selection. Plant Cell Rep. 36, 1917-1928. doi: 10.1007/s00299-017-2206-0

Pasupathy, K., Lin, S., Hu, Q., Luo, H., and Ke, P. C. (2008). Direct plant gene delivery with a poly(amidoamine) dendrimer. Biotechnol. J. 3, 1078-1082. doi: 10.1002/biot.200800021
Pérez-de-Luque, A. (2017). Interaction of nanomaterials with plants: what do we need for real applications in agriculture? Front. Environ. Sci. 5:12. doi: $10.3389 /$ fenvs.2017.00012

Perrault, S. D., Walkey, C., Jennings, T., Fischer, H. C., and Chan, W. C. W. (2009). Mediating tumor targeting efficiency of nanoparticles through design - nano letters. Nano Lett. 9, 1909-1915. doi: 10.1021/nl900031y

Pokhrel, L. R., and Dubey, B. (2013). Evaluation of developmental responses of two crop plants exposed to silver and zinc oxide nanoparticles. Sci. Total Environ. 452-453, 321-332. doi: 10.1016/j.scitotenv.2013.02.059

Racuciu, M. (2012). Iron oxide nanoparticles coated with $\beta$-cyclodextrin polluted of Zea mays plantlets. Nanotechnol. Dev. 2:6. doi: 10.4081/nd.2012.e6

Răcuciu, M., and Creangǎ, D. E. (2009). Cytogenetical changes induced by $\beta$-cyclodextrin coated nanoparticles in plant seeds. Rom. Reports Phys. $54,125-131$.

Rad, F., Mohsenifar, A., Tabatabaei, M., Safarnejad, M. R., Shahryari, F., Safarpour, H., et al. (2012). Detection of Candidatus phytoplasma aurantifolia with a quantum dots fret-based biosensor. J. Plant Pathol. 94, 525-534. doi: 10.4454/JPP.FA.2012.054

Rai, V., Acharya, S., and Dey, N. (2012). Implications of nanobiosensors in agriculture. J. Biomater. Nanobiotechnol. 03, 315-324. doi: 10.4236/jbnb.2012.322039

Raliya, R., Franke, C., Chavalmane, S., Nair, R., Reed, N., and Biswas, P. (2016). Quantitative understanding of nanoparticle uptake in watermelon plants. Front. Plant Sci. 7:1288. doi: 10.3389/fpls.2016.01288

Ranjan, S., Dasgupta, N., and Lichtfouse, E. (2017). Nanoscience in Food and Agriculture 5. Springer International Publishing. doi: 10.1007/978-3-319-58496-6

Rastogi, A., Tripathi, D. K., Yadav, S., Chauhan, D. K., Živčák, M., Ghorbanpour, M., et al. (2019). Application of silicon nanoparticles in agriculture. 3 Biotech 9:90. doi: 10.1007/s13205-019-1626-7

Roduner, E. (2006). Size matters: why nanomaterials are different. Chem. Soc. Rev. 35, 583-592. doi: 10.1039/b502142c

Ruotolo, R., Maestri, E., Pagano, L., Marmiroli, M., White, J. C., and Marmiroli, N. (2018). Plant response to metal-containing engineered nanomaterials: an omics-based perspective. Environ. Sci. Technol. 52, 2451-2467. doi: 10.1021/acs.est.7b04121

Sabo-Attwood, T., Unrine, J. M., Stone, J. W., Murphy, C. J., Ghoshroy, S., Blom, D., et al. (2012). Uptake, distribution and toxicity of gold nanoparticles in tobacco (Nicotiana xanthi) seedlings. Nanotoxicology 6, 353-360. doi: 10.3109/17435390.2011.579631

Saharan, V., Kumaraswamy, R. V., Choudhary, R. C., Kumari, S., Pal, A., Raliya, R., et al. (2016). Cu-chitosan nanoparticle mediated sustainable approach to enhance seedling growth in maize by mobilizing reserved food. J. Agric. Food Chem. 64, 6148-6155. doi: 10.1021/acs.jafc.6b02239

Santos, A. R., Miguel, A. S., Tomaz, L., Malh,ó, R., Maycock, C., Vaz Patto, M. C., et al. (2010). The impact of CdSe/ZnS quantum dots in cells of Medicago sativa in suspension culture. J. Nanobiotechnol. 8:24. doi: 10.1186/1477-3155-8-24

Schwab, F., Zhai, G., Kern, M., Turner, A., Schnoor, J. L., and Wiesner, M. R. (2016). Barriers, pathways and processes for uptake, translocation and accumulation of nanomaterials in plants - Critical review. Nanotoxicology 10, 257-278. doi: 10.3109/17435390.2015.1048326

Serag, M. F., Kaji, N., Gaillard, C., Okamoto, Y., Terasaka, K., Jabasini, M., et al. (2011). Trafficking and subcellular localization of multiwalled carbon nanotubes in plant cells. ACS Nano 5, 493-499. doi: 10.1021/nn102344t

Serag, M. F., Kaji, N., Habuchi, S., Bianco, A., and Baba, Y. (2013). Nanobiotechnology meets plant cell biology: carbon nanotubes as organelle targeting nanocarriers. RSC Adv. 3, 4856-4862. doi: 10.1039/c2ra22766e

Serik, O., Ainur, I., Murat, K., Tetsuo, M., and Masaki, I. (1996). Silicon carbide fiber-mediated DNA delivery into cells of wheat (Triticum aestivum L.) mature embryos. Plant Cell Rep. 16:133-136 doi: 10.1007/BF01890853

Servin, A. D., and White, J. C. (2016). Nanotechnology in agriculture: next steps for understanding engineered nanoparticle exposure and risk. Nano Impact 1 , 9-12. doi: 10.1016/j.impact.2015.12.002

Sharma, P., Bhatt, D., Zaidi, M. G. H., Saradhi, P. P., Khanna, P. K., and Arora, S. (2012). Silver nanoparticle-mediated enhancement in growth and Antioxidant status of Brassica juncea. Appl. Biochem. Biotechnol. 167, 2225-2233. doi: 10.1007/s12010-012-9759-8 
Shen, C. X., Zhang, Q. F., Li, J., Bi, F. C., and Yao, N. (2010). Induction of programmed cell death in Arabidopsis and rice by single-wall carbon nanotubes. Am. J. Bot. 97, 1602-1609. doi: 10.3732/ajb.1000073

Shen, Z., Chen, Z., Hou, Z., Li, T., and Lu, X. (2015). Ecotoxicological effect of zinc oxide nanoparticles on soil microorganisms. Front. Environ. Sci. Eng. 9, 912-918. doi: 10.1007/s11783-015-0789-7

Shi, J., Yang, Y., Hu, T., Yuan, X., Peng, C., Chen, Y., et al. (2013). Phytotoxicity and accumulation of copper oxide nanoparticles to the $\mathrm{Cu}$-tolerant plant Elsholtzia Splendens. Nanotoxicology 8, 179-188. doi: 10.3109/17435390.2013. 766768

Simonin, M., Richaume, A., Guyonnet, J. P., Dubost, A., Martins, J. M. F., and Pommier, T. (2016). Titanium dioxide nanoparticles strongly impact soil microbial function by affecting archaeal nitrifiers. Sci. Rep. 6:33643. doi: $10.1038 /$ srep33643

Song, U., Jun, H., Waldman, B., Roh, J., Kim, Y., Yi, J., et al. (2013). Functional analyses of nanoparticle toxicity: a comparative study of the effects of $\mathrm{TiO} 2$ and Ag on tomatoes (Lycopersicon esculentum). Ecotoxicol. Environ. Saf. 93, 60-67. doi: 10.1016/j.ecoenv.2013.03.033

Sun, D., Hussain, H. I., Yi, Z., Siegele, R., Cresswell, T., Kong, L., et al. (2014). Uptake and cellular distribution, in four plant species, of fluorescently labeled mesoporous silica nanoparticles. Plant Cell Rep. 33:1389-1402. doi: 10.1007/s00299-014-1624-5

Tanaka, Y., Kimura, T., Hikino, K., Goto, S., Nishimura, M., Mano, S., et al. (2012). "Gateway vectors for plant genetic engineering: overview of plant vectors, application for Bimolecular Fluorescence Complementation (BiFC) and multigene construction," in Genetic Engineering - Basics, New Applications and Responsibilities, ed H. Barrera-Saldaña (Mexico: Universidad Autónoma de Nuevo León), 64. doi: 10.5772/32009

Tang, B. Z., Wang, Y., Podsiadlo, P., and Kotov, N. A. (2006). Biomedical applications of layer-by-layer assembly : from biomimetics to tissue engineering. Adv. Mater. 2136, 3203-3224. doi: 10.1002/adma.200600113

Tarafdar, J. C., Raliya, R., Mahawar, H., and Rathore, I. (2014). Development of zinc nanofertilizer to enhance crop production in pearl millet (Pennisetum americanum). Agric. Res. 3, 257-262. doi: 10.1007/s40003-014-0113-y

Torney, F., Trewyn, B. G., Lin, V. S. Y., and Wang, K. (2007). Mesoporous silica nanoparticles deliver DNA and chemicals into plants. Nat. Nanotechnol. 2, 295-300. doi: 10.1038/nnano.2007.108

Valenstein, J. S., Lin, V. S.-Y., Lyznik, L. A., Martin-Ortigosa, S., Wang, K., Peterson, D. J., et al. (2013). Mesoporous silica nanoparticle-mediated intracellular cre protein delivery for maize genome editing via loxP site excision. PLANT Physiol. 164, 537-547. doi: 10.1104/pp.113.233650

Valletta, A., Chronopoulou, L., Palocci, C., Baldan, B., Donati, L., and Pasqua, G. (2014). Poly(lactic-co-glycolic) acid nanoparticles uptake by Vitis vinifera and grapevine-pathogenic fungi. J. Nanoparticle Res. 16, 1917-1928. doi: 10.1007/s11051-014-2744-0

Verma, S. K., Das, A. K., Patel, M. K., Shah, A., Kumar, V., and Gantait, S. (2018). Engineered nanomaterials for plant growth and development: a perspective analysis. Sci. Total Environ. 630, 1413-1435. doi: 10.1016/j.scitotenv.2018.02.313

Vidyalakshmi, N., Thomas, R., Aswani, R., Gayatri, G. P., Radhakrishnan, E. K., and Remakanthan, A. (2017). Comparative analysis of the effect of silver nanoparticle and silver nitrate on morphological and anatomical parameters of banana under in vitro conditions. Inorg. Nano Metal Chem. 47, 1530-1536. doi: 10.1080/24701556.2017.1357605
Viswanath, B., and Kim, S. (2015). Influence of nanotoxicity on human health and environment: the alternative strategies. Rev. Environ. Contam. Toxicol. 240, 77. doi: $10.1007 / 398$

Waalewijn-Kool, P. L., Ortiz, M. D., Lofts, S., and van Gestel, C. A. (2013). The effect of ph on the toxicity of zinc oxide nanoparticles to folsomia candida in amended field soil. Environ. Toxicol. Chem. 32, 2349-2355. doi: $10.1002 /$ etc. 2302

Wang, K., Drayton, P., Frame, B., Dunwell, J., and Thompson, J. (1995). Whiskermediated plant transformation: an alternative technology. Vitr. Cell. Dev. Biol. Plant 31, 101-104. doi: 10.1007/BF02632245

Wang, P., Lombi, E., Zhao, F. J., and Kopittke, P. M. (2016). Nanotechnology: a new opportunity in plant sciences. Trends Plant Sci. 21:699-712. doi: 10.1016/j.tplants.2016.04.005

Wang, T., Bai, J., Jiang, X., and Nienhaus, G. U. (2012). Cellular uptake of nanoparticles by membrane penetration: a study combining confocal microscopy with FTIR spectroelectrochemistry. ACS Nano. 6:1251-1259. doi: $10.1021 / \mathrm{nn} 203892 \mathrm{~h}$

Wang, Z., Xu, L., Zhao, J., Wang, X., White, J. C., and Xing, B. (2016). $\mathrm{CuO}$ nanoparticle interaction with arabidopsis thaliana: toxicity, parentprogeny transfer, and gene expression. Environ. Sci. Technol. 50, 6008-6016. doi: 10.1021/acs.est.6b01017

Whiteside, M. D., Treseder, K. K., and Atsatt, P. R. (2009). The brighter side of soils: Quantum dots track organic nitrogen through fungi and plants. Ecology 90, 100-108. doi: 10.1890/07-2115.1

Yao, K. S., Li, S. J., Tzeng, K. C., Cheng, T. C., Chang, C. Y., Chiu, C. Y., et al. (2009). Fluorescence silica nanoprobe as a biomarker for rapid detection of plant pathogens. Adv. Mater. Res. 79-82, 513-516. doi: 10.4028/www.scientific.net/AMR.79-82.513

Zhai, G., Walters, K. S., Peate, D. W., Alvarez, P. J. J., and Schnoor, J. L. (2014). Transport of gold nanoparticles through plasmodesmata and precipitation of gold ions in woody poplar. Environ. Sci. Technol. Lett. 1, 146-151. doi: 10.1021/ez400202b

Zhao, X., Meng, Z., Wang, Y., Chen, W., Sun, C., Cui, B., et al. (2017). Pollen magnetofection for genetic modification with magnetic nanoparticles as gene carriers. Nat. Plants 3, 956-964. doi: 10.1038/s41477-017-0063-Z

Zheng, L., Hong, F., Lu, S., and Liu, C. (2005). Effect of Nano-TiO2 on strength of naturally aged seeds and growth of spinach. Biol. Trace Elem. Res. 104, 083-092. doi: 10.1385/BTER:104:1:083

Zhu, Z. J., Wang, H., Yan, B., Zheng, H., Jiang, Y., Miranda, O. R., et al. (2012). Effect of surface charge on the uptake and distribution of gold nanoparticles in four plant species. Environ. Sci. Technol. 46, 12391-12398. doi: $10.1021 /$ es301977w

Conflict of Interest Statement: The authors declare that the research was conducted in the absence of any commercial or financial relationships that could be construed as a potential conflict of interest.

Copyright (c) 2019 Sanzari, Leone and Ambrosone. This is an open-access article distributed under the terms of the Creative Commons Attribution License (CC BY). The use, distribution or reproduction in other forums is permitted, provided the original author(s) and the copyright owner(s) are credited and that the original publication in this journal is cited, in accordance with accepted academic practice. No use, distribution or reproduction is permitted which does not comply with these terms. 